\title{
суицидология
}

УДК 616.89-008.441.44:343.148.3-053.66(571.54):81’366.521(1-22):332.37:159.922.33/.36

Для цитирования: Лубсанова С.В., Тудупова Т.Ц., Батуева Н.Г. Основные характеристики завершенных суицидов несовершеннолетних в Республике Бурятия (по материалам судебно-психиатрической экспертизы). Сибирский вестник психиатрии и наркологии. 2018; 4 (101): 81-86. https://doi.org/10.26617/1810-3111-2018-4(101)-81-86

\section{Основные характеристики завершенных суицидов несовершеннолетних в Республике Бурятия (по материалам судебно-психиатрической экспертизы) Лубсанова С.В.' ${ }^{1}$ Тудупова Т.Ц..', Батуева Н.Г. ${ }^{2}$}

\author{
${ }^{1}$ Бурятский государственный университет \\ Россия, 670000, Улан-Удэ, ул. Смолина, 24 а \\ 2 Республиканский психоневрологический диспансер \\ Россия, 670000, Улан-Удэ, ул. Рабочая, Іа
}

\section{PEЗЮME}

В статье приведены результаты ретроспективного анализа посмертных актов комплексной судебной психологопсихиатрической экспертизы завершенных суицидов детей и подростков в Республике Бурятия за период 2012-2016 гг. По данным анализа в структуре завершенных суицидов преобладают подростки, в возрасте 15-17 лет, мужского пола, проживающие в сельской местности, воспитывающиеся в неполной семье, обучающиеся в среднеобразовательной школе. В $21,8 \%$ случаев имела место отягощенная наследственность по суициду у близких родственников. Каждый пятый ребенок-суицидент имел признаки суицидального поведения ранее (суицидальные высказывания, попытки, интерес к теме суицида). В большинстве из имеющихся случаев вероятными причинами суицидального поступка являются семейные конфликты. Проведенный анализ позволил определить перечень признаков, которые необходимо освещать в актах посмертных экспертиз детей и подростков, совершивших суицид.

Ключевые слова: суицид, детско-подростковый суицид, региональный аспект суицидального поведения, комплексная судебная психолого-психиатрическая экспертиза.

\section{ВВЕДЕНИЕ}

Частота самоубийств является одним из наиболее важных и объективных индикаторов социального состояния страны, показателем общественного психического здоровья и качества жизни населения. На протяжении последнего десятилетия XX века Россия входила в число стран с высоким показателем суицидов (свыше 20 случаев на 100 тыс. населения). В настоящее время, начиная с 2002 г., отмечается положительная тенденция по снижению коэффициента смертности от суицидов. По данным Росстата, в 2015 г. впервые зарегистрирован показатель 17,4 случая на 100 тыс. населения и постепенное снижение в дальнейшем: в 2016 г. - 15,6, в 2017 г. 13,7 , что соответствует среднему уровню суицидальной активности.

Разносторонний анализ суицидального поведения проводился многими отечественными исследователями [1, 2, 3, 4, 5, 6, 7]. Несмотря на разнообразие подходов и изменчивость расставляемых акцентов, многие авторы подчеркивают в своих работах многофакторность феномена суицидального поведения. Обсуждается, что уровень суицидов зависит от социально-экономической ситуации региона, демографических, биологических, этнокультуральных и личностных факторов.

Одним из важнейших демографических показателей является возраст. В этой связи не может не вызывать тревогу тот факт, что подростковый суицид формирует первый подъем в кривой распреде- ления суицидальной активности. Поведение детей и подростков, а тем более суицид, является прямым отражением микро- и макросоциальных процессов, происходящих вокруг ребенка. На Всероссийской конференции «Психическое здоровье детей страны - будущее здоровье нации» (Ярославль, 2016) Е.В. Макушкин высказал общее мнение участников о том, что «...суицид ребенка и подстрекательство к суицидоопасному поведению подростка - реальные угрозы национальной безопасности».

В соответствии с данными Следственного управления СК РФ в 2015 г. было зарегистрировано 685 случаев суицидов среди детей и подростков, в 2016 г. - 720 случаев. Распределение показателей суицидальной активности на территории РФ очень неравномерное. Есть регионы с нулевой суицидальностью, такие как Республика Ингушетия. Другие регионы отличаются сверхвысоким уровнем суицидов, например Чукотский автономный округ (23,7 случая на 100 тыс. населения).

Республика Бурятия на протяжении последнего десятилетия устойчиво входит в тройку лидеров по показателю смертности по причине суцицида. В 2016 г. уровень завершенных суицидов среди несовершеннолетних (0-17 лет) в Республике Бурятия составил 10,5 (для сравнения: 7,6 случая в Республике Алтай и 6,3 случая в Забайкальском крае). В группе несовершеннолетних подавляющее большинство суицидов приходится на подростковый возраст. 
Так, в Бурятии в 2013 г. среди контингента детей 0-14 лет зафиксировано 3,5 случая завершенных суицидов, а подростковых суицидов - 33 случая; в 2014 г. - 3 и 42 случая соответственно; в $2015-3,2$ и 28,6; в 2016 г. - 3,2 и 63,6 (по данным мониторинга завершённых суицидов РБ).

Суицид несовершеннолетних представляет собой особо трагическое общественное явление, сложность понимания которого обусловлена возрастными особенностями мышления, незрелостью эмоциональной сферы и несформированными поведенческими конструктами. В последнее время в литературе публикуется большое количество работ, посвященных проблемам детско-подростковых суицидов, рассматриваемых с позиций теоретико-концептуального подхода к данному феноменологическому явлению $[8,9,10,11,12]$. Возрастные особенности суицидального поведения детей и подростков наслаиваются на региональную специфику, особенности микросоциального окружения, что в целом формирует мировоззрение и стиль поведения, характерные для определенного места проживания. Проведено достаточное количество исследований, изучающих особенности детско-подростковых суицидов, влияние острых психотравм на уровень социализации и психологическое реагирование подростков в различных региональных субъектах РФ $[13,14,15,16,17,18,19,20]$.

Необходимо подчеркнуть, что, несмотря на «особые приметы» суицида несовершеннолетних, данный раздел суицидологии сталкивается с проблемами, являющимися общими для суицидологии в целом, и связаны они со структурной сложностью рассматриваемого явления. Говоря о теоретической обоснованности рассмотрения суицидального поведения, следует отметить то, что изучение суицидального поведения сосредоточено преимущественно в аспектном рассмотрении гуманитарных наук. Авторы консолидируют весь теоретический материал в следующие основные концепции: социальную, биологическую, психологическую и интегративную.

В психологических теориях, которые составляют самую многочисленную группу, ведущее место занимают психологические факторы и подчеркивается роль агрессии, направленной на себя. Особое место среди психологических теорий занимает когнитивное направление, которое, на наш взгляд, как нельзя лучше сочетает в себе возможности объективизации и фундаментализации последующих исследований. Подтверждением тому может служить фокусирование на когнитивном подходе ряда зарубежных программ, посвященных психокоррекции и превенции суицидального поведения детей и подростков (A. Spirito, J.D. Matthews, A. Wenzel, A.T. Beck) [21, 22, 23, 24]. Определению концептуально-базисных подходов при рассмотрении детско-подростковых суицидов, адаптации и реабилитации суицидентов и их микросоциального окружения посвящены работы А.Б. Холмогоровой $[24,25]$, Т.С. Павловой, Г.С. Банникова [26].
Таким образом, имеются основания говорить об активизации, концептуальном сплочении исследователей в направлении изучения детско-подростковых суицидов, так как данное явление представляет не только социальную значимость в масштабах российского общества, но и значимость для каждого конкретного человека, сталкивающегося с этой системной проблемой.

На территории Республики Бурятия анализ завершенных детско-подростковых суицидов проводится впервые.

\section{ЦЕЛЬ ИССЛЕДОВАНИЯ}

Провести комплексный анализ детскоподростковых завершенных суицидов в Республике Бурятия в 2012-2016 гг.

\section{МАТЕРИАЛ И МЕТОДЫ}

Проведен ретроспективный анализ по материалам 78 актов комплексной судебной психологопсихиатрической экспертизы с данными о завершенных случаях суицидов детей и подростков по Республике Бурятия за период 2012-2016 гг. Оценку суицидальных актов осуществляли по следующим критериям: возраст, пол, место проживания, уровень образования, характеристика состава семьи, способ суицида, возможные мотивы и причины (если таковое было указано в актах), личный и семейный суицидальный анамнез, а также наличие психических заболеваний у суицидентов и их родных.

Исследование проводилось с помощью клиникостатистического метода. Статистическая обработка данных произведена с использованием «Statistica 10.0 for Windows».

\section{РЕЗУЛЬТАТЫ И ИХ ОБСУЖДЕНИЕ.}

Общее количество проанализированных актов 78. В связи с тем, что не во всех актах отражены исследуемые критерии, абсолютные значения анализируемых актов по отдельным признакам могут различаться.

Количество мальчиков и юношей за весь период (2012-2016 гг.) преобладало и составило 45 человек $(61,5 \%)$, девочек и девушек - 30 (38,5\%). При этом в возрастную категорию до 14 лет вошло 33 (42,3\%) ребенка, а 15-17 лет - 45 (57,7\%) (табл. 1).

Т а б ли ц а 1

Распределение суицидентов по полу и возрасту

\begin{tabular}{|c|c|c|}
\hline \multirow{2}{*}{ Пол } & \multicolumn{2}{|c|}{ Возраст } \\
\cline { 2 - 3 } & $0-14$ лет & $15-17$ лет \\
\hline Мальчики/юноши & $21(26,9 \%)$ & $27(34,6 \%)$ \\
\hline Всего & \multicolumn{2}{|c|}{$45(61,5 \%)$} \\
\hline Девочки/девушки & $12(15,4 \%)$ & $18(23,1 \%)$ \\
\hline Всего & \multicolumn{2}{|c|}{$30(38,5 \%)$} \\
\hline
\end{tabular}

В структуре завершенных суицидов ведущую позицию занимают юноши в возрасте 15-17 лет. При внутригрупповом распределении (в группе детей и группе подростков) мальчики преобладают над девочками. Из общего числа суицидентов большинство $(64,1 \%$ - 50 человек) проживали в сельской местности, более трети подростков $(35,9 \%$ - 28 человек) были городскими жителями. 
Оценить полученный уровень образования удалось в 74 актах, в 4 актах место обучения не было указано. Так, 57 (77\%) детей и подростков обучалось в среднеобразовательных школах, из них 50\% (37 человек) являлись учащимися сельских школ и $27 \%$ - городских. Учащимися коррекционных школ было 6 человек $(8,1 \%)$, в профессиональных училищах обучалось 10 человек $(13,5 \%)$. Среди студентов небольшой перевес был на стороне сельских жителей $-8,1 \%$. Один ребенок нигде не обучался (табл. 2).

Т а б ли ц а 2 Распределение суицидентов по уровню образования $(n=74)$

\begin{tabular}{|c|c|c|c|c|}
\hline $\begin{array}{c}\text { Место } \\
\text { прожива- } \\
\text { ния }\end{array}$ & $\begin{array}{c}\text { Общеобра- } \\
\text { зователь- } \\
\text { ная школа }\end{array}$ & $\begin{array}{c}\text { онрекция- шко- } \\
\text { ла }\end{array}$ & $\begin{array}{c}\text { Професси- } \\
\text { ональное } \\
\text { училище }\end{array}$ & $\begin{array}{c}\text { Не обуча- } \\
\text { ется }\end{array}$ \\
\hline Город & $20(27 \%)$ & $6(8,1 \%)$ & $4(5,4 \%)$ & - \\
\hline $\begin{array}{c}\text { Сельская } \\
\text { местность }\end{array}$ & $37(50 \%)$ & - & $6(8,1 \%)$ & $1(1,4 \%)$ \\
\hline Всего & $57(77 \%)$ & $6(8,1 \%)$ & $10(13,5 \%)$ & $1(1,4 \%)$ \\
\hline
\end{tabular}

Семейная ситуация в 40,3\% случаев (31 человек) характеризовалась как благополучная: дети проживали в полных семьях, материально удовлетворительно. Вместе с тем 37 детей (48\%) воспитывались в неполных семьях, при этом к данной категории мы отнесли и те случаи, когда брак родителей был официально зарегистрирован, но они проживали отдельно или ребенок воспитывался мачехой, отчимом и имелись указания на конфликтные отношения в семье. В приемных семьях воспитывалось 7 детей $(9,1 \%)$, двое были сиротами $(2,6 \%)$ и находились на воспитании у родственников-опекунов (табл. 3 ).

Т а б ли ц а 3

Распределение суицидентов по составу семьи $(\mathbf{n}=77)$

\begin{tabular}{|c|c|c|c|c|}
\hline Возраст & $\begin{array}{c}\text { Полная } \\
\text { семья }\end{array}$ & $\begin{array}{c}\text { Неполная } \\
\text { семья }\end{array}$ & $\begin{array}{c}\text { Приемная } \\
\text { семья }\end{array}$ & Опекуны \\
\hline $0-14$ лет & $12(15,6 \%)$ & $16(20,8 \%)$ & $4(5,2 \%)$ & - \\
\hline $15-17$ лет & $19(24,7 \%)$ & $21(27,2 \%)$ & $3(3,9 \%)$ & $2(2,6 \%)$ \\
\hline Всего & $31(40,3 \%)$ & $37(48,0 \%)$ & $7(9,1 \%)$ & $2(2,6 \%)$ \\
\hline
\end{tabular}

Изучение способов совершения самоубийства как в группе детей, так и в группе подростков показало, что лидирует механическая асфиксия - 65 $(85,6 \%)$ суицидентов выбрали именно повешение как способ ухода из жизни; 7 человек $(9,2 \%)$ - медикаментозное отравление, 3 (3,9\%) - падение с высоты и 1 случай $(1,3 \%)$ - применение огнестрельного оружия. У каждого пятого несовершеннолетнего суицидента (21,8\% случаев - 17 человек) согласно материалом уголовного дела, свидетельским показаниям в анамнезе обнаружены признаки суицидального поведения (тревожные высказывания, попытки в прошлом, повышенный интерес к теме суицида, разговоры о смерти). Вместе с тем была ли им предложена или оказана помощь в состоянии сильном эмоционального напряжения (со стороны родственников, близких, специалистов) не известно, так как указаний на это в актах нет.
При качественной оценке микросоциального окружения в актах отмечено, что в 9 семьях $(11,5 \%)$ имелись случаи завершенного суицида у ближайших родственников (родители, дедушки, родные дяди). Очевидно, вероятность суицида напрямую связана и с тем, что в 21,8\% (17 семей) случаев родители (или один из родителей) страдали алкоголизмом. Официальных данных о наличии у кого-то из родных психического заболевания в актах не приведено. Но в 8 случаях из 78 (10,2\%) имело место наличие комплекса факторов риска суицида у ребенка. Это и неполная семья, и наличие алкоголизма и суицидов у ближайших родственников, и суицидальное поведение у самого ребенка в прошлом, и изменение текущего психологического состояния, и наличие психотравмирующей ситуации, т.е. почти каждую десятую смерть можно было предотвратить, если бы ближайшее окружение было осведомлено о том, на что в первую очередь необходимо обратить внимание. Ведь в $50 \%$ случаев (39 человек) по данным заключения судебнопсихиатрической экспертизы, материалам уголовного дела имеются указания на то, что состояние суицидентов незадолго до смерти изменилось: окружающие отмечали появление замкнутости, снижение настроения, раздражительности, безнадежности. Некоторые подростки раздавали долги, просили прощения за обиды, что раныше им было не свойственно, другая часть подростков стали необычно агрессивными, обидчивыми, вели себя вызывающе. Предсмертные записки обнаружены в единичных случаях (3 человека). В качестве вероятной причины (мотива) суицида в 7 случаях указаны конфликты в емье, в 5 случаях - конфликтные отношения со сверстниками, по 3 случая приходится на неразделенную любовь и трудности в обучении, 2 суицида произошло после того добровольного ухода из жизни лучшего друга. В качестве возможных причин однократно указывался алкоголизм родителей, инвалидность после травмы и неспособность справиться с последствиями болезни, потеря родителей в результате несчастного случая. Сведения о совершении суицида в состоянии алкогольного опьянения, когда у подростков была снижена способность контролировать свои эмоции и поведение, несмотря на их важность, представлены только в 2 актах. К сожалению, сделать выводы в этнокультуральном аспекте не представляется возможным, так как в проанализированных актах отсутствуют указания на этническую принадлежность суицидентов, а делать выводы на основании такого формального признака как фамилия - значит, заведомо искажать факты.

\section{ЗАКЛЮЧЕНИЕ}

Анализ завершенных детско-подростковых суицидов на территории Республики Бурятия позволил сформировать выводы в двух направлениях. Первое из них соответствует заявленным целям - получена социально-демографическая характеристика суицидов среди детей и подростков РБ за 2012-2016 гг. 
Если уместно говорить о среднестатистическом «портрете суицидента» то можно сказать, что это юноша-подросток, обучающийся в общеобразовательной школе, проживающий в сельской местности, в неполной или приемной семье, выбирающий как способ ухода из жизни повешение и демонстрирующий признаки изменения поведения перед совершением суицида. У каждого четвертого совершившего суицид несовершеннолетнего имелся родственник, покончивший жизнь самоубийством. Каждый четвертый подросток так или иначе демонстрировал внешние признаки суицидального поведения. Вместе с тем такой поверхностный усредненный подход не может быть единственно применим при рассмотрении такого сложного и многостороннего вопроса, как детский суицид.

И здесь уместно говорить о другом направлении выводов, которые сформировались помимо исполнения непосредственной задачи. Имеется в виду необходимость структурирования актов судебнопсихиатрической экспертизы по завершенным суицидам. Структура должна содержать оптимально максимальное число признаков, описывающих динамику развития суицидального акта, индивидуально-психологические характеристики ребенка, расширенный перечень социально-демографических характеристик с подробным описанием семейного окружения, стиля воспитания, условий и психологического климата обучения, ведь почти $80 \%$ покончивших собой несовершеннолетних были школьниками. Крайне необходима этническая составляющая описания, так как это позволит глубже понять региональную специфику детских суицидов и повысить количество точек приложения превентивных мер. Все описываемые признаки должны быть формализованы, что позволит более качественно проводить количественный и содержательный анализ, который, в свою очередь, будет являться основой для разработки превенции с учетом регионального и этнокультурального аспектов. Основной объем профилактических мер должен разрабатываться для применения их в сфере образования и работы с семьей. Педагогический состав должен быть ориентирован в вопросах определения первых признаков аутоагрессивного поведения и алгоритма своих действий в таких ситуациях. Профилактика же в семье, по нашему мнению, предполагает несколько другую направленность: превентивные меры должны реализовываться через механизмы формирования конструктивных форм совладающего поведения. Прямая направленность мер и повышение настороженности родителей в отношении суицидального поведения детей могут иметь обратный эффект в силу эмоциональной значимости и привести к гипермерам со стороны родителей.

Таким образом, полное, комплексное, структурированное изучение характеристик суицидального поведения с учетом регионального компонента является необходимым условием для действенной превенции.

\section{КОНФЛИКТ ИНТЕРЕСОВ}

Авторы декларируют отсутствие явных и потенциальных конфликтов интересов в связи с публикацией данной статьи.

\section{ИСТОЧНИК ФИНАНСИРОВАНИЯ}

Исследование основных характеристик завершенных суицидов несовершеннолетних выполнено при поддержке гранта РФФИ «Междисциплинарное исследование причин и региональных факторов суицидального поведения несовершеннолетних» 18 013-00620A.

\section{ЛИТЕРАТУРА}

1. Войцех В.Ф. Динамика и структура самоубийств в России. Социальная и клиническая психиатрия. 2006; 16 (3): 22-27.

2. Дмитриева Т.Б., Положий Б.С. Социальные и клинические проблемы суицидологи в системе мер по снижению преждевременной смертности и увеличению продолжительности жизни населения. Вестник Российской академии медицинских наук. 2006; 8: 18-22.

3. Положий Б.С. Суицидальная ситуация в современной России. Профилактика заболеваний и укрепление здоровья. 2007; 5: 16-17.

4. Положий Б.С. Интегративная модель суицидального поведения. Российский психиатрический журнал. 2010; 4: 55-62.

5. Морев М.В., Шматова Ю.Е., Любов Е.Б. Динамика суицидальной смертности населения России: региональный аспект. Суицидология. 2014; 5 (1): 3-11.

6. Чистопольская К.А., Ениколопов С.Н., Магурдумова Л.Г. Медико-психологические и социально-психологические концепции суицидального поведения. Суицидология. 2013; 4 (3): $17-25$

7. Руженков В.А., Руженкова В.В., Боева А.В. Концепции суицидального поведения. Суицидология. 2012; 3 (4): 52-60.

8. Положий Б.С., Панченко Е.А. Суициды у детей и подростков в России: современная ситуация и пути её нормализации. [Электронный ресурс]. Медицинская психология в России: электронный научный журнал. 2012; 2. URL:http ://medpsy.ru (дата обращения 01.03.2018)

9. Павлова Т.С., Банников Г.С. Современные теории суицидального поведения подростков и молодежи [Электронный ресурс]. Психологическая наука и образование. 2013; 4. URL:http://psyedu.ru/journal/2013/4/Pavlova_Bannikov.phtml (дата обращения 01.03.2018)

10. Банников Г.С., Павлова Т.С., Кошкин К.А., Летова А.В. Потенциальные и актуальные факторы риска развития суицидального поведения подростков (обзор литературы). Суииидология. 2015; 6 (4): 21-32.

11. Лукашук А.В., Филиппова М.Д., Сомкина О.Ю. Характеристика детских и подростковых суицидов (обзор литературы). Российский медико-биологический вестник имени академика И.П. Павлова. 2016; 2: 137-143.

12. Сыроквашина К.В. Современные психологические модели суицидального поведения в подростковом возрасте. Консультативная психология и психотерапия. 2017; 25 (3): 6075.

13. Ворсина О.П. Суицидальные попытки детей и подростков в г. Иркутске. Суицидология. 2011; 2: 28-29.

14. Барыльник Ю.Б., Бачило Е.В., Антонова А.А. Структура завершенных и незавершенных суицидов на территории Саратовской области. Суицидология. 2011; 4: 37-41.

15. Злова Т.П., Ишимбаева А.Н., Ахметова И.И. Социальнопсихологические особенности незавершенных суицидов у детей и подростков (Забайкальский край, г. Чита). Суицидология. 2011; 2: 26-28.

16. Спадерова Н.Н., Горохова О.В., Герасина С.Е. Анализ завершенных суицидов у детей и подростков в практике отделения амбулаторных судебно-психиатрических экспертиз Тюменской ОКПБ за 2012-2014 гг. Тюменский медицинский журнал. 2014; 16 (1): 21-24.

17. Селезнев С.Б. К вопросу о суицидальной активности детей и подростков Краснодарского края. Тюменский медицинский журнал. 2014; 16 (1): 18-20. 
18. Кирпиченко А.А., Барышев А.Н. Суицидальное поведение подростков г. Витебска и Витебской области. Вестник Вuтебского государственного университета. 2015; 14 (2): 7782.

19. Семенова Н.Б. Особенности эмоциональной сферы коренной молодежи Севера как фактор риска суицидального поведения. Суицидология. 2011; 2: 11-13.

20. Семенова Н.Б., Мартынова Т.Ф. Анализ завершенных суицидов среди детей и подростков Республики Саха (Якутия) Сибирский вестник психиатрии и наркологии. 2012: 3 (72): 42-45.

21. Beck A.T. et al. Hopelessness and eventual suicide. Am. J. Psychiatry. 1985; 142 (5): 559-63.

22. Shneidman E.S. Deaths of man. New York: Quadrangle, 1973: 238.

23. Spirito A., Esposito-Smythers C., Wolff J. Cognitive-Behavioral Therapy for Adolescent Depression and Suicidality. Child. Adolsc. Psychiatric Clin. N. Am.. 2011; 20: 191-204.
24. Wenzel A., Beck A.T. A cognitive model of suicidal behavior: Theory and treatment. Applied and Preventive Psychology. 2008; 12: 189-201.

25. Холмогорова А.Б., Воликова С.В. Основные итоги исследований факторов суицидального риска у подростков на основе психосоциальной многофакторной модели расстройств аффективного спектра [Электронный ресурс]. Медицинская психология в России: электронный научный журнал. 2012; 2 (13). URL:http ://medpsy.ru (дата обращения 01.03.2018)

26. Холмогорова А.Б. Когнитивная психотерапия суицидального поведения: история разработки, современное состояние, перспективы развития [Электронный ресурс]. Медицинская психология в России: электронный научный журнал. 2013; 2 (19). URL:http://medpsy.ru (дата обращения 01.03.2018)

Поступила в редакцию 14.05.2018 Утверждена к печати 6.11.2018

Лубсанова Светлана Викторовна, кандидат медицинских наук, доцент кафедры инфекционных болезней медицинского факультета (SPIN-код: 9294-3313, Author ID: 656023).

Тудупова Туяна Цибановна, кандидат психологических наук, доцент, заведующая кафедрой общей и социальной психологии социальнопсихологического факультета (SPIN-код: 8093-6615, Author ID: 503407)

Батуева Наталья Григорьевна, кандидат медицинских наук, заведующая судебно-психиатрическим экспертным отделением (SPIN-код: 2443-9697).

\title{
Лубсанова Светлана Викторовна, 1sv1972@ mail.ru
}

УДК 616.89-008.441.44:343.148.3-053.66(571.54):81’366.521(1-22):332.37:159.922.33/.36

For citation: Lubsanova S.V., Tudupova Ts.T., Batueva N.G. The main characteristics of completed suicides of minors in the Republic of Buryatia (based on forensic psychiatric examination). Siberian Herald of Psychiatry and Addiction Psychiatry. 2018; 4 (101): 81-86. https://doi.org/10.26617/1810-3111-2018-4(101)-81-86

\section{The main characteristics of completed suicides of minors in the Republic of Buryatia (based on forensic psychiatric examination) Lubsanova S.V.', Tudupova Ts.T.', Batueva N.G. ${ }^{1},{ }^{2}$}

\author{
${ }^{1}$ Buryat State University \\ Smolin Street 24a, 670000, Ulan-Ude, Russian Federation \\ ${ }^{2}$ Republican Psychoneurological Dispensary \\ Rabochaya Street la, Ulan-Ude, Russian Federation
}

\section{ABSTRACT}

The article presents the results of retrospective analysis of postmortem acts of complex judicial psychological and psychiatric examination of completed suicides of children and adolescents in the Republic of Buryatia for the period 2012-2016. According to the analysis, the structure of the completed suicides is dominated by male adolescents (15-17 years), living in rural areas, brought up in one-parent family, enrolled in secondary school. In $21.8 \%$ of the cases there is family history of suicide and every fifth suicidal child had signs of suicidal behavior earlier (suicidal statements, attempts, interest in the topic of suicide). In most of the available cases, the likely causes of suicide are family conflicts. In addition, the analysis allows to identify the list of missing features that need to be covered in the acts of postmortem examinations of children and adolescents who commit suicide.

Keywords: suicide, adolescent suicide, regional aspect of suicidal behavior, complex forensic psychological and psychiatric examination.

\section{REFERENCES}

1. Voytsekh V.F. Dinamika i struktura samoubijstv v Rossii [Dynamics and structure of suicides in Russia]. Social'naya $i$ klinicheskaya psihiatriya - Social and Clinical Psychiatry. 2006; 16 (3): 22-27 (in Russian).

2. Dmitrieva T.B., Polozhy B.S. Social'nye i klinicheskie problemy suicidologi $\mathrm{V}$ sisteme mer po snizheniyu prezhdevremennoj smertnosti i uvelicheniyu prodolzhitel'nosti zhizni naseleniya [Social and clinical problems suicidologists in the system of measures to reduce premature mortality and increase life expectancy]. Vestnik RAMN - Bulletin of the Russian Academy of Medical Sciences. 2006; 8: 18-22 (in Russian).

3. Polozhy B.S. Suicidal'naya situaciya v sovremennoj Rossii [The suicidal situation in modern Russia]. Profilaktika zabolevanij $i$ ukreplenie zdorov'ya - Disease Prevention and Health Promotion. 2007; 5: 16-17 (in Russian).

4. Polozhy B.S. Integrativnaya model' suicidal'nogo povedeniya [Integrative model of suicidal behavior]. Rossijskij psihiatricheskij zhurnal - Russian Journal of Psychiatry. 2010; 4: 55-62 (in Russian).

5. Morev M.V., Shmatova Yu.E., Lyubov E.B. Dinamika suicidal'noj smertnosti naseleniya Rossii: regional'nyj aspect [Dynamics of suicidal mortality in Russia: regional aspect]. Suicidologiya-Suicidology. 2014; 5 (1): 3-11 (in Russian).

6. Chistopol'skaya K.A., Enikolopov S.N., Magurdumova L.G. Mediko-psihologicheskie i social'no-psihologicheskie koncepcii suicidal'nogo povedeniya [Medical-psychological and socio- 
psychological concepts of suicidal behavior]. Suicidologiya Suicidology. 2013; 4 (3): 17-25 (in Russian).

7. Ruzhenkov V.A., Ruzhenkova V.V., Boeva A.V. Koncepcii suicidal'nogo povedeniya [Concepts of suicidal behavior]. Suicidologiya - Suicidology. 2012; 3 (4): 52-60 (in Russian).

8. Polozhy B.S., Panchenko E.A. Suicidy u detej i podrostkov v Rossii: sovremennaya situaciya i puti eyo normalizacii [Ehlektronnyj resurs] [Suicide among children and adolescents in Russia: the current situation and ways to normalize it. [Electronic resource]. Medicinskaya psihologiya v Rossii: ehlektron. nauch. zhurnal - Medical Psychology in Russia: electronic scientific journal. 2012; 2. URL:http://medpsy.ru (data obrashcheniya 01.03.2018) (in Russian).

9. Pavlova T.S., Bannikov G.S. Sovremennye teorii suicidal'nogo povedeniya podrostkov i molodezhi [Modern theories of suicidal behavior of adolescents and youth]. Psihologicheskaya nauka obrazovaniye - Psychological Science and Education. 2013. № 4. URL:http ://psyedu.ru /journal/ 2013 / 4 / Pavlova_Bannikov.phtml (date of appeal 01.03.2018) (in Russian).

10. Bannikov G.S., Pavlova T.S., Koshkin K.A., Letova A.V. Potencial'nye i aktual'nye faktory riska razvitiya suicidal'nogo povedeniya podrostkov (obzor literatury) [Potential and actual risk factors for the development of suicidal behavior in adolescents (literature review)]. Suicidologiya - Suicidology. 2015; 6 (4): 21-32 (in Russian).

11. Lukashuk A.V., Filippova M.D., Somkina O.YU. Harakteristika detskih i podrostkovyh suicidov (obzor literatury) [Characteristics of child and adolescent suicides (literature review)]. Rossijskij mediko-biologicheskij vestnik imeni akademika I.P. Pavlova - Russian Medical and Biological Bulletin named after academician I.P. Pavlov. 2016; 2: 137-143 (in Russian).

12. Syrokvashina K.V. Sovremennye psihologicheskie modeli suicidal'nogo povedeniya $\mathrm{v}$ podrostkovom vozraste [Modern psychological models of suicidal behavior in adolescence]. Konsul'tativnaya psihologiya i psihoterapiya - Counseling Psychology and Psychotherapy. 2017; 25 (3): 60-75 (in Russian).

13. Vorsina O.P. Suicidal'nye popytki detej i podrostkov v g. Irkutske [Suicide attempts of children and adolescents in Irkutsk]. Suicidologiya - Suicidology. 2011; 2: 28-29 (in Russian).

14. Baryl'nik Yu.B., Bachilo E.V., Antonova A.A. Struktura zavershennyh i nezavershennyh suicidov na territorii Saratovskoj oblasti [The structure of completed and uncompleted suicides in the Saratov region]. Suicidologiya - Suicidology. 2011; 4: 37-41 (in Russian).

15. Zlova T.P., Ishimbaeva A.N., Akhmetova I.I. Social'nopsihologicheskie osobennosti nezavershennyh suicidov u detej i podrost-kov (Zabajkal'skij kraj, g. Chita) [Socio-psychological characteristics of incomplete suicides in children and adolescents (Zabaikalsky Krai, Chita)]. Suicidologiya - Suicidology. 2011; 2: 26-28 (in Russian)

16. Spaderova N.N., Gorokhova O.V., Gerasina S.E. Analiz zavershennyh suicidov u detej i podrostkov v praktike otdeleniya ambulatornyh sudebno-psihiatricheskih ehkspertiz Tyumenskoj OKPB za 2012-2014 gg. [Analysis of completed suicides in children and adolescents in the practice of the Department of outpatient forensic psychiatric examinations of the Tyumen OKPB for 2012-2014]. Tyumenskij medicinskij zhurnal - Tyumen Medical Journal. 2014; 16 (1): 21-24 (in Russian).

17. Seleznev S.B. K voprosu o suicidal'noj aktivnosti detej i podrostkov Krasnodarskogo kraya [On the issue of suicidal activity of children and adolescents of Krasnodar region]. Tyumenskij medicinskij zhurnal - Tyumen Medical Journal. 2014; 16 (1): 18-20 (in Russian).

18. Kirpichenko A.A., Baryshev A.N. Suicidal'noe povedenie podrostkov g. Vitebska i Vitebskoj oblasti [Suicidal behavior of adolescents in Vitebsk and Vitebsk region]. Vestnik Vitebskogo gosudarstvennogo universiteta - Bulletin of Vitebsk State University. 2015; 14 (2): 77-82 (in Russian).

19. Semenova N.B. Osobennosti ehmocional'noj sfery korennoj molodezhi Severa kak faktor riska suicidal'nogo povedeniya [Features of the emotional sphere of indigenous youth of the North as a risk factor for suicidal behavior]. Suicidologiya - Suicidology. 2011; 2: 11-13 (in Russian).

20. Semenova N.B., Martynova T.F. Analiz zavershennyh suicidov sredi detej i podrostkov Respubliki Saha (Yakutiya) [Analysis of completed suicides among children and adolescents of the Republic of Sakha (Yakutia)]. Sibirskij vestnik psihiatrii $i$ narkologii - Siberian Herald of Psychiatry and Addiction Psychiatry. 2012; 3: 42-45 (in Russian).

21. Beck A.T. et al. Hopelessness and eventual suicide. Am. J. Psychiatry. 1985; 142 (5): 559-63.

22. Shneidman E.S. Deaths of man. New York: Quadrangle, 1973. $238 \mathrm{p}$.

23. Spirito A., Esposito-Smythers C., Wolff J. Cognitive-Behavioral Tnerapy for Adolscent Depression and Suicidality. Child. Adolsc. Psychiatric Clin. N. Am. 2011; 20: 191-204.

24. Wenzel A., Beck A.T. A cognitive model of suicidal behavior: Theory and treatment. Applied and Preventive Psychology. 2008; 12: 189-201.

25. Kholmogorova A.B., Volikova S.V. Osnovnye itogi issledovanij faktorov suicidal'nogo riska u podrostkov na osnove psihosocial'noj mnogofaktornoj modeli rasstrojstv affektivnogo spektra [Ehlektronnyj resurs] [The main results of studies of suicide risk factors in adolescents based on psychosocial multifactorial model of affective spectrum disorders [Electronic resource]. Medicinskaya psihologiya $v$ Rossii: ehlektron. nauch. zhurnal Medical Psychology in Russia: electronic scientific journal. 2012; 2 (13). URL:http ://medpsy.ru (date of access 01.03.2018) (in Russian).

26. Kholmogorova A.B. Kognitivnaya psihoterapiya suicidal'nogo povedeniya: istoriya razrabotki, sovremennoe sostoyanie, perspektivy razvitiya [Ehlektronnyj resurs] [Cognitive psychotherapy of suicidal behavior: development history, current state, development prospects [Electronic resource]. Medicinskaya psihologiva $v$ Rossii: ehlektron. nauch. zhurnal-Medical Psychology in Russia: electronic scientific journal. 2013; 2 (19). URL:http ://medpsy.ru (date of access 01.03.2018) (in Russian).

Received May 14.2018 Accepted November 6.2018

Lubsanova Svetlana V., PhD, associate professor, Department of Infectious Diseases, Medical Faculty, Buryat State University, Ulan-Ude, Russian Federation (SPIN-code: 9294-3313, Author ID: 656023).

Tudupova Tuyana Ts., candidate of psychological sciences, docent, Head of Department of General and Social Psychology, Social-psychological Faculty, Buryat State University, Ulan-Ude, Russian Federation (SPIN-code: 8093-6615, Author ID: 503407).

Batueva Natalia G., PhD, Head of Forensic Psychiatric Expert Department, Buryat State University, Ulan-Ude, Russian Federation; Republican Psychoneurological Dispensary, Ulan-Ude, Russian Federation (SPIN-code: 2443-9697). 